\title{
Sociedades modernas, sociedades de obsolescência: a sociologia temporal de Hartmut Rosa
}

ROSA, Hartmut. Aceleração: a transformação das estruturas temporais na modernidade. São Paulo: Editora Unesp, 2019.

\section{Pedro Frizo* (D) Wagner Nascimento**}

\section{Resumo}

Centrado na revisitação da modernidade a partir de uma perspectiva temporal, Hartmut Rosa sustenta o conceito de aceleração social como aspecto fundante do projeto moderno. Explorando diferentes variáveis causais para o conceito da aceleração social, a resenha examina as transformações das instituições morais, valorativas e políticas ocorridas ao longo do desenvolvimento histórico da modernidade como episódios induzidos pela obsolescência. Sendo esta um produto de campos de ação crescentemente cambiantes e acelerados, o autor mobiliza esse conceito para fundamentar inédita proposta de diferenciação entre a modernidade e a modernidade tardia como momentos históricos calcados em diferentes níveis de compressão espaço-temporal, estabilidade institucional e temporalização de projetos individuais e coletivos de futuro.

Palavras-chave: Hartmut Rosa, aceleração, modernidade, instituições.

\footnotetext{
* Instituto Conexões Sustentáveis - Conexsus, Rio de Janeiro, RJ, Brasil.

** Universidade Federal do Rio Grande do Sul, Porto Alegre, RS, Brasil.
} 


\section{Modern societies, obsolescence societies: Hartmut Rosa's temporal sociology}

\section{Abstract}

Centered on revisiting modernity from a temporal perspective, Hartmut Rosa supports the concept of social acceleration as a fundamental aspect of the modern project. Exploring different causal variables for the concept of social acceleration, the review examines the transformations of moral, valuative and political institutions that occurred during the historical development of modernity as episodes induced by obsolescence. As this is a product of increasingly changing and accelerated fields of action, the author mobilizes this concept to substantiate an unprecedented proposal for differentiation between modernity and late modernity as historical moments based on different levels of space-time compression, institutional stability and temporalization of individual and collective future projects.

Keywords: Hartmut Rosa, Acceleration, Modernity, Institutions.

revisitação de temas consagrados nas Ciências Sociais é exercício
analítico interessante ao propor novos olhares sobre o que já foi
extensamente estudado em tempos anteriores, demandando, no entanto, intensa revisão teórica e conceitual para a efetiva sustentação de argumentos inéditos. Nesse sentido, Hartmut Rosa, em seu mais novo livro publicado no Brasil (2019), Aceleração: a transformação das estruturas temporais na Modernidade, proporciona ao leitor uma obra repleta de sólidas argumentações, referências teóricas e dados sobre a Modernidade a partir do prisma epistemológico da Sociologia do Tempo, consistindo em um estudo contemporâneo potente sobre um tema dos mais clássicos da sociologia e instaurador do saber sociológico.

Tendo-se em vista o fato de a Sociologia ser a disciplina mais solidamente envolvida com a reflexão sobre a vida social moderna (Giddens, 1991), o projeto o qual Hartmut Rosa se impôs representa tarefa complexa. Afinal, o estudo da modernidade foi tomado como tema central de análise tanto pelos pais fundadores - Karl Marx, Émile Durkheim e Max Weber - quanto por teóricos contemporâneos, tais como Jurgen Habermas, Talcott Parsons 
e Niklas Luhmman - apenas para citar alguns - cada qual com sua maneira específica de conceituação da modernidade e de seus efeitos sobre as formas objetivas de vida e de subjetivação individual. Propor, portanto, uma nova tese analítica sobre este tema é tarefa que exige não somente franco diálogo com esses e outros autores consagrados, mas também uma construção cuidadosa e inovadora do argumento teórico-analítico que se deseja sustentar.

Em Aceleração, Rosa explora os requisitos necessários para uma boa fundamentação de sua tese principal, a saber, de que "a mutação das estruturas espaço-temporais [na Modernidade] é impulsionada, de forma primária, pela sua dinâmica transformacional temporal" (Rosa, 2019, p. 59 , adendo nosso). As quatro partes do livro trazem uma leitura crítica da literatura existente sobre o tempo como variável sociológica, fundamentam os conceitos trabalhados na obra e exploram as causas e consequências da intensa aceleração moderna, estabelecendo um fio condutor necessário e congruente para o leitor compreender, essencialmente, como as manifestações e transformações tão características do projeto moderno como a diferenciação social, a racionalização e a individualização - são variáveis cuja leitura analítica sobre suas origens é indissociável de uma compreensão mais aprofundada de suas relações com o regime temporal moderno.

Nesse sentido, a Parte I da obra nos apresenta uma inversão na relação de determinação entre as variáveis dependentes e independentes que sempre estiveram em jogo na conceituação da Modernidade: enquanto autores clássicos posicionaram a diferenciação, a racionalização, a domesticação e a individualização como elementos que inauguraram o projeto moderno, Rosa os apresenta, antes, como possíveis "estratégias de aceleração", sendo a própria aceleração temporal a gênese primária das sociedades modernas. Quer dizer, se para Weber (1904 [2004]) uma das consequências da ética ascética protestante era justamente a ausência de desperdício de tempo e eliminação do ócio (racionalização), ou se para Simmel (1900 [2004]) um dos efeitos do dinheiro era confluir, em uma mesma unidade, todas 
as possibilidades de escolha e de vivências, intensificando as relações sociais e econômicas entre os indivíduos (individualização), para Rosa tais processos modernos configuram-se como consequências de uma estratégia transcendente de aceleração social.

Conceituar a aceleração social é, dessa maneira, tarefa importante dentro da tese proposta por Rosa. Para tanto, partindo de uma simples definição - mobilizando para isso noções da Física Mecânica - da aceleração social como aumento de quantidade por unidade de tempo, o autor sustenta o conceito-chave do livro a partir de uma importante distinção entre volume de ações por unidade de "recurso temporal" à disposição. Assim, teremos a seguinte fórmula:

\section{$a=\frac{\Delta V}{\Delta t}(1)$}

Onde,

$\mathrm{a}=$ taxa de aceleração;

$\mathrm{V}=$ Velocidade (i.e., ritmo de volume de ações);

$\mathrm{t}=$ Tempo (i.e., recursos temporais à disposição para execução das ações).

Logo, a aceleração social representa um aumento quantitativo de $\mathrm{V}$ a taxas superiores aos recursos temporais à disposição para a execução das ações referentes.

Dessa maneira, a Modernidade é caracterizada pelo crescimento quantitativo nos campos de ação - conceito empregado pelo autor para referir-se aos diferentes espaços institucionais de ação social - frente o tempo que se tem à disposição para participação nos mesmos e execução das ações determinadas. É essencial atentar-se à assimetria entre as taxas de crescimento das unidades de ação e as unidades de recurso temporal 
à disposição para a compreensão exata da tese central do autor a respeito da constante aceleração social moderna.

Avançando ao longo do texto sobre a gênese da dinâmica aceleratória moderna, o autor apresenta três dimensões da aceleração social e, sobre elas, constrói os capítulos seguintes da obra: a aceleração técnica, a aceleração da mudança social e a aceleração do ritmo de vida. Em verdade, a existência de uma dimensionalidade tripartite materializa em bases empiricamente verificáveis o argumento central desenvolvido por Rosa sobre a aceleração social moderna como um processo de aumento vertiginoso de campos de ação frente aos recursos temporais à disposição dos indivíduos. Embora as dimensões sejam apresentadas na Parte I, será na Parte II que o autor irá explorar com mais afinco cada dimensão e suas formas de efetuação e manifestação social e subjetiva.

É importante pontuar, antes de explorar a definição conceitual por trás de cada dimensão, a endogeneidade do processo aceleratório. As três dimensões - a "aceleração técnica", a "aceleração da mudança social" e a "aceleração do ritmo de vida" - são, na visão do autor, vetores autorregressivos, isto é, mutuamente correlacionados. Nesse sentido, a aceleração técnica é variável dependente da aceleração no ritmo de vida, a qual, por sua vez, se apresenta como dimensão associada à aceleração da mudança social, cuja existência refere-se à aceleração técnica. Estabelecese, assim, um ciclo aceleratório vicioso que dificulta a definição de qual dimensão principia o estudo sobre a aceleração social na modernidade, uma vez que uma dimensão, inevitavelmente, nos leva às outras duas dimensões associadas.

No caso da aceleração técnica, a partir da compartilhada noção de escassez de tempo frente a um ritmo de vida que aumenta a taxas gradativamente alucinantes, a inovação em produtos e processos aparece como grandes ganhos de economia temporal. A partir das inovações técnicas ocorridas na história humana e, especificamente, dentro do projeto moderno, o ser humano modificou sua relação com o espaço, a sociedade e a matéria. No âmbito espacial, inovações nas formas de locomoção de pessoas e 
mercadorias redefiniram a noção sobre o tamanho relativo dos espaços. De acordo com o autor, na Modernidade Tardia, o tempo desvincula-se definitivamente do espaço e ganha autonomia própria sobre este último, na medida em que se calcula a distância entre dois pontos não mais, de forma prioritária, a partir de unidades de medida espacial, mas sim com base em horas e minutos.

No que diz respeito às transformações na relação do ser com a sociedade, inovações nos modelos de comunicação aceleraram a forma pela qual as informações circulam, intensificando, por consequência, a velocidade com que escolhas são tomadas e transformações são geradas a partir de dados que, em tempos anteriores, tardariam a ser conhecidos por pessoas e grupos espacialmente distantes. No âmbito das relações com a materialidade da vida - ou, nas palavras do autor, com as "coisas" -, a crescente necessidade de intensificação na circulação do capital impõe um elevado ritmo não somente de produção, mas também de consumo - instância em que, de fato, se realiza o valor excedente, retornando o capital para posterior reaplicação no processo produtivo. A competição por mercados e consumidores também implica um elevado ritmo de inovações em produtos, expondo consumidores, de maneira recorrente, a um infindável leque de mercadorias à disposição.

Assim, meios de transporte e de comunicação, bem como bens, serviços, modos e meios de produção aparecem como objetos transitórios frente à constante pressão por inovação técnica e economia de tempo. Compreende-se, de forma socialmente difundida, que os processos sociais de relação com o espaço, as pessoas e as coisas são passageiros frente à iminente possibilidade de desenvolvimento, no curto prazo, de novas rotinas de ação. A compartilhada noção entre os agentes de que os campos de ação em que estão inseridos são unidades de obsolescência previsível fundamenta uma imanente necessidade, então, de se "estar um passo à frente" de mudanças tomadas como dadas e esperadas, estabelecendo o que o autor denomina como um fenômeno de paralisia frenética: estado reativo em que se empreendem esforços enormes de adaptação às transformações 
e, desejavelmente, antecipação às mesmas, sem implicar, necessariamente, em melhorias nas condições de vida ou de posição ocupada na hierarquia social. Em outras palavras, o indivíduo se move e se transforma em um ritmo demasiadamente acelerado, para estar, simplesmente, no mesmo lugar que ocupa.

A partir da perspectiva de que a Modernidade é marcada, então, pela estruturação de campos de obsolescência, Rosa avalia os aspectos centrais da influência desta conjuntura sobre os padrões de relação social e associativa entre indivíduos e grupos, abrindo as portas para compreender a sua segunda dimensão analítica: a aceleração da mudança social. A base para a compreensão dessa dimensão remete ao estado transitório pelo qual espaços, pessoas e coisas assumem em uma conjuntura em que a transformação é, em qualquer momento, iminente:

Através disso fica claro o quanto as acelerações dos transportes, da comunicação e da produção influenciaram os sujeitos em suas autorrelações e suas relações para com o mundo e, com isso, os modelos de identidade socialmente relevantes. A identificação com espaços, com parceiros de comunicação fixos, com grupos de referência e com as coisas assume um caráter temporalmente limitado e contingente - o sujeito é forçado a distanciar-se ou emancipar-se deles de modo que possa suportar uma mudança (voluntária ou obrigatória) sem a perda do eu (Rosa, 2019, p. 206-207, nosso grifo).

O excerto acima apresenta com clareza o desprendimento individual de normas, padrões, valores, estruturas e procedimentos - isto é, instituições - que poderiam operar como instâncias definidoras da identidade social, uma vez que, a qualquer momento, estes mesmos balizadores institucionais podem se converter em unidades obsoletas. Fica claro, portanto, que a esse gradativo processo de desvinculação e desapego subjaz, como fator causal, a inovação técnica e o desenvolvimento constante da matriz de escolhas e instrumentos à disposição do ser.

O autor define, metaforicamente, a transitoriedade do sistema de orientadores da ação social e das práticas como uma sensação subjetiva de viver sobre "declives escorregadios", ou seja, uma condição de eterna 
mutação na "paisagem" de decisões possíveis dentro dos campos de ação, de tal forma que não é mais possível saber quais ações e escolhas serão realizáveis e congruentes no futuro próximo. Com efeito, a metáfora é adequada para facilitar a compreensão da maneira pela qual a aceleração da mudança social está correlacionada à aceleração do ritmo de vida. Quer dizer, o ritmo de execução de ações se eleva exponencialmente a partir do estado transitório e obsoleto dos campos de ação, de tal forma que manter uma rotina diária em ritmo estático ou mesmo similar a períodos anteriores representa uma perda imensurável de oportunidades, de possibilidades de antecipação de futuras mudanças e de posições sociais. Dessa forma, a aceleração do ritmo de vida é essencial para a compreensão mais exata da ideia de paralisia frenética, estado pelo qual o "amor ao movimento" demonstra a sua origem estrutural e cultural. Para Rosa, portanto, se fossemos definir uma ontologia do ser moderno, seria uma ontologia que contemple a ideia do ser como reativo à obsolescência, um ser cujas ações são constantemente tomadas como medidas para evitá-la.

Com a adoção crescente de múltiplas tarefas (multitasking) e rotinas diárias aceleradas, a pressão para que haja maior liberação de tempo aos indivíduos aumenta significativamente. Inovações técnicas, novos produtos ou processos são tomados socialmente como aspectos chave para que a elevada quantidade de ações a serem desempenhadas tomem menos tempo para serem executadas, liberando um volume de recursos temporais significativo. É através dessa compartilhada crença sobre o papel temporal da inovação que Rosa consolida sua teia de relações interdependentes entre aceleração da mudança social, aceleração do ritmo de vida e aceleração técnica.

No entanto, associar as causas das mudanças objetivas e subjetivas que a aceleração social manifesta na Modernidade Tardia unicamente através do processo autopropulsor será, de acordo com o autor, compreender o fenômeno aceleratório somente através daquilo que o faz reproduzível ao longo do tempo. Quer dizer, a aceleração técnica, da mudança social e do ritmo de vida são fatores que explicam a razão pela qual o ciclo 
de "aumento de quantidades" (Rosa, 2019, p. 320) a taxas superiores aos recursos temporais liberados se propaga, sem, no entanto, explicar fundamentalmente o que eleva de fato as quantidades (tal como expressa a equação [1]) a um patamar de crescimento vertiginoso. Cada parte do tripé autopropulsor possui uma variável externa que o fundamenta para além de sua própria relação de dependência causal com as outras duas dimensões da aceleração social. Ou seja: a aceleração técnica possui sua gênese também, nas palavras do autor, no "motor econômico"; a do ritmo de vida encontra suas raízes de forma igualmente importante no "motor cultural"; a da mudança social no "motor socioestrutural". Sobre cada uma dessas relações de influência iremos discorrer brevemente.

Em relação ao motor econômico e sua fundamentação da aceleração técnica, o capitalismo pode ser definido, em termos temporais, como sistema de produção, distribuição e consumo de mercadorias e serviços calcado na exploração dos recursos temporais individuais e familiares. Para o autor, o próprio Marx fez questão de ressaltar que o sistema capitalista não compra, essencialmente, a força de trabalho em si, mas sim o tempo em que o indivíduo passa, então, a se dedicar à produção de mercadorias e serviços que futuramente serão convertidos, no mercado, em lucro ao capitalista (Marx, 1867 [2011]), não utilizando mais de seu tempo para execução de tarefas e ofícios de seu interesse genuíno. A partir do momento em que a produção pela produção centraliza e controla significativa parte dos recursos temporais, apresentando-se como um grande imperativo sistêmico da Modernidade Tardia, ela o trata como tempo indiscriminado e meramente como unidade quantitativa, cuja manipulação aritmética em horas e dias é fundamental na mensuração e aprimoramento da produtividade do capital. Retornando à equação [1], um modo de produção será tanto mais competitivo quanto mais acelerado ele for, ou seja, quanto maior for o volume de produção sobre uma mesma unidade de tempo.

Para além das inovações técnicas, o autor exemplifica diversas instituições que foram criadas, ao longo da Modernidade Tardia, com o propósito de acelerar o tempo necessário para a circulação total do 
capital. A contradição do ciclo aceleratório está, por sua vez, no fato de que, em certo momento da história moderna, as instituições e os processos técnicos que perduraram transitoriamente como instâncias virtuosas para a circulação do capital passam, subitamente, a ser compreendidas como "freios". Um exemplo apresentado por Rosa é o próprio regime de trabalho "fordista" que, se num primeiro momento acelerou o ritmo de produção, a certa altura foi visto como entrave à aceleração produtiva, sendo assim superado. Mais além, no texto, o autor retrata como o Estado moderno, instituição indissociável à história do próprio capitalismo, também passa a ser visto, sob o jugo do neoliberalismo econômico, como barreira ao desenvolvimento capitalista.

O aspecto dual que as instituições assumem será, para Rosa, um fator chave para compreender como a aceleração é o principal motor da história econômica moderna. Ela, em verdade, se faz preenchida por uma sequência de episódios de emergência, contestação e superação de procedimentos, protocolos, técnicas, hábitos e rotinas de ação aceleratórias, remetendo, nesta proposição analítica, ao próprio Marx e sua irrevogável necessidade de conceder uma unidade epistemológica à história social através da perspectiva do materialismo histórico.

Seria uma compreensão equivocada e reducionista sobre o autor, no entanto, apontar que sua proposição da aceleração como motor da história social refere-se, exclusivamente, à aceleração de cunho técnico, intimamente conectada com a dimensão econômica. Mencionando rapidamente a proibição moral da perda de tempo como possível motor cultural, o autor logo ruma à estruturação dos fatores existenciais-culturais em bases mais sólidas do que um mandamento moral fundamentado exclusivamente na proibição. Para além do medo e repreensão, a ideia de "promessa" é mobilizada como alicerce moral da cultura aceleratória. Em primeiro lugar, argumenta o autor a partir de uma clara referência a Simmel e sua Filosofia do Dinheiro (Simmel, 1900 [2004]), a substituição secular de Deus pela moeda posiciona-a como a divina providência na Modernidade, ou seja, aquela que tudo traz e tudo concede. A aceleração da propriedade 
de dinheiro através de novos processos incrementa não somente o poder social do indivíduo, mas recai, moralmente, como promessa futura de segurança e providência.

Como último pilar externo, relacionado de forma primária com a aceleração da mudança social, o autor mostra como a crescente diferenciação social opera uma lógica aceleratória dentro da Modernidade Tardia - processo que ele define como motor socioestrutural. A existência de múltiplos campos de ação aumenta a quantidade de espaços sociais em que o indivíduo precisa negociar com os demais a sua participação. A gestão do tempo para estar presente em vários lugares e em desempenhar diversas funções e papeis sociais culmina, como sintoma essencial, na priorização dos prazos em detrimento daquilo que efetivamente concede prazer ou satisfação ao indivíduo. Nesse sentido, negociações temporais com familiares e amigos, ou mesmo a alocação de tempo menor em repertórios de comportamento que não estejam vinculados ao trabalho são ações cada vez mais características do ser moderno.

Com a crescente contração do tempo, os campos de ação sofrem interferências exógenas, no sentido de que as operações aí existentes devem ser aceleradas com o objetivo de liberar uma quantidade de recurso temporal maior ao indivíduo, de tal forma que esta liberação permita a ele existir no cotidiano acelerado de outros campos. Portanto, acelera-se a interação com familiares, amigos e em atividades de lazer para, em última instância, dar conta de possuir tempo suficiente para desempenhar ações satisfatórias no campo do trabalho, da política ou da educação profissional, por exemplo. Em resumo, o motor socioestrutural está na relação entre o aumento quantitativo de escolhas e ações possíveis com a temporalização necessária para a execução das mesmas.

A imensa dificuldade de temporalização das escolhas em face da instituição cada vez mais arraigada de um estado de transitoriedade das coisas, pessoas e espaços, empurra o ser à condição de uma vida "destemporalizada" ou, como o autor também coloca, "situacionalizada". Presenciando um câmbio constante na paisagem de decisões, o indivíduo 
é estimulado a adotar um "comportamento situacional": suas escolhas ocorrem segundo opções disponíveis e cenários calculados no momento, excluindo qualquer possibilidade de adotar um comportamento estável ao longo do tempo. Mesmo a identidade, definida a partir de sua relação com os objetos, grupos e instituições da vida social, assume a condição de "identidade situacional", construída em um contexto cambiante de referências identitárias. A esta "individualidade puntiforme", ressalta o autor, desvincular-se-á qualquer associação a predicados, consolidando um estado em que não faz sentido afirmar "quem se é", mas sim ressaltar "quem se está" (neste momento).

A transitoriedade identitária será, para Rosa, um dos argumentos para a construção de sua definição própria da Pós-Modernidade, entendida como período de supressão das identidades fixas e, somado a isto, de uma renúncia ao direcionamento político e normativo da sociedade. Ou seja, a "condição pós-moderna" será, em última instância, um período "no qual a aceleração instituída na Modernidade Tardia ultrapassa um ponto crítico, ou assume uma nova qualidade, de tal maneira que a linearidade e a sequencialidade da percepção e da elaboração, individual e social, de problemas e transformações, são rompidas, e a pretensão de integração é abandonada" (Rosa, 2019, p. 447). Vale ressaltar que a palavra "integração" no excerto acima se refere, principalmente, à integração sequencial dos eventos históricos em um processo acumulativo e direcionado da história social e a como a sequencialidade dos fatos históricos perde qualquer noção de direcionalidade maior no atual estágio de desenvolvimento social.

Ao protagonismo generalizado da situacionalidade em detrimento da estabilidade de identidades sociais, temos a ideia de "destemporalização", no sentido de que narrativas e histórias pessoais não mais mobilizam os recursos temporais como elemento-chave para a construção da própria identidade e das vontades políticas, mas sim compreendem o tempo como um processo descolado de qualquer construção de sentido unívoco. Ou seja, na medida em que o ser constrói noções identitárias (de quem se é) a partir do passado (quem se foi) e do futuro (quem se quer ser), e entendendo que 
a noção de quem se é se constrói em diálogo relacional com os elementos espaciais do mundo, bem como com o conjunto de pessoas e grupos com os quais se interage, a identidade social sofre intensa transformação a partir do momento em que espaço-tempo sofrem imensa contração. Em contraposição à Modernidade Clássica, quando a individualidade se assumia como um projeto a ser construído no tempo ("escolha de identidade") contra a herança de posições sociais fixas da Pré-Modernidade ("prescrição de identidade"), a condição pós-moderna resume a destemporalização da individualidade à emergência de trajetórias errantes, sem nenhuma noção fundamental de processo acumulativo de construção da história pessoal.

A política, por sua vez, assume uma similar condição de instância destemporalizada. Originalmente, na Modernidade Clássica o Estado fora visto como o principal condutor de um projeto de emancipação e progresso a ser construído no tempo, em uma concepção da história como sequência de fatos dinâmicos, especialmente através de instituições básicas tomadas como essenciais para a aceleração dos ganhos sociais, tais como a democracia e a burocracia. A desvinculação, no entanto, entre o tempo da política e o do funcionamento do jogo democrático com a aceleração dos processos sociais e econômicos estimula a existência de uma compreensão socialmente difundida de extrema morosidade estatal frente aos "avanços necessários" para o desenvolvimento social. A partir de algumas evidências empíricas, o autor pontua o crescente protagonismo do Executivo, através de um ritmo maior de instituição de decretos sobre as leis formais, frente a uma gradativa descrença e desmoralização do Legislativo.

Em face da insatisfação social com o papel do Estado democrático na condução do desenvolvimento social, a condição pós-moderna é caracterizada, então, pela constante pressão erosiva sobre os fundamentos democráticos - antes, na história, compreendidos como dínamos do processo aceleratório, hoje entendidos como freios. Para o autor, a própria inversão da polarização política é uma manifestação única da Modernidade Tardia, no sentido de que progressistas - os quais na Modernidade Clássica defendiam uma aceleração maior da transformação social - passam, na 
contemporaneidade, a posicionar-se como frente defensora de uma maior desaceleração; ao passo que conservadores - os quais na Modernidade Clássica eram defensores da conservação da ordem social frente às "ameaças" do desenvolvimento - representam a principal frente aceleratória.

Fundamentar o conceito de Modernidade a partir de uma perspectiva temporal, em que a aceleração do tempo aparece como elemento chave para compreender subjetividades e padrões de desenvolvimento social do projeto moderno, é uma tarefa que Aceleração executa com primor, oferecendo ao leitor provocações e reflexões importantes sobre as causas, formas de efetuação e consequências - em níveis individual e estrutural do intenso processo aceleratório moderno e da condição pela qual opera - no limite - a Modernidade Tardia. Até que ponto o processo aceleratório será possível, isto é, qual a margem possível de aumento nos episódios de ação, se os recursos temporais, ao invés de liberados, parecem cada vez mais exíguos?'1

Por fim, a partir de uma perspectiva sistêmica sobre o seu lugar de produção, Aceleração se junta à obra de uma série de cientistas sociais contemporâneos - especialmente da escola alemã - conectados, teóricometodologicamente, não somente à sociologia do tempo, mas sim à centralidade analítica do conceito de futuro como ideia-força subjacente às sociedades modernas e capitalista. Dentro desse rol de autores, destacamos Jens Beckert (2016) e seu conceito de futuros imaginados como talvez a interface mais imediata a um dos argumentos centrais na obra analisada de Rosa: a fundamentação de um projeto temporalizado como aspecto fundante dos campos de ação e sua destemporalização como variável socialmente

\footnotetext{
${ }^{1}$ Quatro possíveis saídas à trajetória crescente de aceleração são discutidas pelo autor, o qual tão logo refuta a viabilidade de implementação das mesmas. São elas: (I) criação de uma nova ordem institucional que eleve, de fato, o ritmo dos processos sociais, conservando e estabilizando o processo de aceleração e, com isso, retornando a um estágio similar ao da Modernidade Clássica; (II) renúncia definitiva ao projeto moderno e acolhimento total das subjetividades e condição pós-moderna; (III) intervenção política efetiva para retardação da dinâmica aceleratória em prol de uma "ressincronização"; e (IV) continuidade do processo aceleratório, o que levaria, de acordo com o autor, a uma ruína efetiva das ordens social, política e ecológica.
} 
desestabilizante. A abertura para que novos estudos investiguem, com mais afinco, as possíveis intersecções entre proposições analíticas sobre o tempo e suas respectivas formas de efetuação, consiste em uma das frentes teóricas de maior relevância para a revisitação, na contemporaneidade, de temas clássicos da sociologia.

Pedro Frizo é Mestre em Sociologia pela Universidade Federal do Rio Grande do Sul (UFRGS) e consultor em cadeias de valor agrícolas e extrativistas, junto ao Instituto Conexões Sustentáveis - Conexsus.

$\bowtie$ pedro.frizo@gmail.com

Wagner Lemes do Nascimento é doutorando do Programa de Pós-Graduação em Sociologia na Universidade Federal do Rio Grande do Sul (UFRGS).

$\bowtie$ wagner.lemes39@gmail.com

\section{Referências}

1. BECKERT, Jens. Imagined futures. Cambridge: Harvard University Press, 2016.

2. GIDDENS, Anthony. As consequências da modernidade. São Paulo: Editora UNESP, 1991.

3. MARX, Karl. O Capital: Livro I. São Paulo: Boitempo Editorial, 2011.

4. ROSA, Hartmut. Aceleração: a transformação das estruturas temporais na modernidade. São Paulo: Editora Unesp, 2019.

5. SIMMEL, Georg. The philosophy of money. Londres: Routledge, 2004.

6. WEBER, Max. A ética protestante e o espírito do capitalismo. São Paulo: Companhia das Letras, 2004. 